being these will remain the province of the research worker.

Measurement of adhesion and spreading in macrophages appears to reflect phagocytic potential, and in animals these functions increase with macrophage activation. ${ }^{10}$ Tests of chemotaxis, phagocytosis, and micro-organism killing have been shown to be abnormal in a variety of conditions. For example, monocyte chemotaxis is defective in patients with mucocutaneous candidiasis ${ }^{11}$ and some carcinomas ${ }^{12}$ and in the Chediak-Higashi syndrome. ${ }^{13}$ There are reports of reduced monocyte microbial activity in chronic granulomatous disease, ${ }^{14}$ chronic neutropenia, ${ }^{15}$ and myeloperoxidase deficiency, ${ }^{16}$ and in patients receiving high-dose corticosteroid treatment. ${ }^{17}$ Monocyte phagocytosis is depressed in some patients with Hodgkin's disease and lymphosarcoma. ${ }^{18}$ Others have found that monocytes from most patients with myelomonocytic leukaemia and some patients with lymphoma phagocytose bacteria normally but do not kill intracellular bacteria. ${ }^{19}$

For the moment, monocyte function tests may not be of much direct benefit to patient care. Nevertheless, further defects associated with disease states will emerge only as these tests become more reliable and are more widely applied.

${ }^{1}$ Metchnikoff, E, Immunity in Infective Diseases. London, Cambridge University Press, 1905

2 Aschoff, L, Lectures on Pathology. New York, Hoeber, 1924.

3 Lewis, M R, American fournal of Pathology, 1925, 1, 91.

4 Ebert, R H, and Florey, H W, British fournal of Experimental Pathology, $1939,20,342$.

5 Evans, R, and Alexander, P, Nature, 1972, 236, 168.

6 Hibbs, J B, Lambert, L H, and Remington, J S, Science, 1972, 177, 998.

${ }^{7}$ Chervenick, P A, and Lo Buglio, A F, Science, 1972, 178, 164.

${ }^{8}$ Golde, D W, and Cline, M J, fournal of Clinical Investigation, 1972, 51, 2981.

9 Territo, M C, and Cline, M J, fournal of Immunology, 1977, 118, 187

10 David, J R, Federation Proceedings, 1975, 34, 1730.

11 Snyderman, R L C, et al, Annals of Internal Medicine, 1973, 78, 509.

12 Snyderman, R, and Stahl, C, in The Phagocytic Cell in Host Resistance, eds J A Bellanti and D H Dayton. New York, Raven Press, 1975.

13 Gallin, J I, et al, Blood, 1975, 45, 863.

14 Davis, W C, et al, fournal of Immunology, 1968, 101, 1093.

15 Lehrer, R I, and Cline, M J, fournal of Clinical Investigation, 1969, 48, 1478.

${ }^{16}$ Baehner, R L, and Johnston, R B, Blood, 1972, 40, 31.

17 Rinehart, J J, et al, New England fournal of Medicine, 1975, 292, 236.

18 Ghosh, M L, Hudson, G, and Blackburn, E K, British fournal of Haematology, 1973, 25, 293.

${ }^{19}$ Cline, M J, fournal of Clinical Investigation, 1973, 52, 2185.

\section{Bigger outlet for the bile duct?}

Surgeons are all too familiar with the problem of residual stones in the common bile duct. Once the decision is made to explore the common duct there are two aims: to remove all of the stones and to prevent further stone formation.

Most often the bile duct is explored by an opening in the supraduodenal portion, but this practice is mechanically unsound. Clearly, the most effective way of removing particulate matter from a narrow tube is to open one end rather than making a hole half way along it. Exploration of the biliary ducts through the ampulla of Vater has its exponents, but they remain a minority, ${ }^{1}$ probably because the common duct is much easier to find and enter above the duodenum.

After they have removed stones from the common bile duct many surgeons rely on the passage of bougies and saline irrigation to ensure complete clearance. Unfortunately, using these methods alone, they will overlook stones in up to $10 \%$ of patients. ${ }^{2}$ Two ways are available for confirming that the duct is completely clear while the patient is still on the operating table. With careful technique ${ }^{3}$ useful postexploratory cholangiograms (which are worth while even though they are not as accurate as pre-exploratory films) can usually be obtained, though the contrast may fail to enter the duodenum simply as a result of the passage of bougies through the ampulla of Vater. More recently, direct examination of the duct with a choledochoscope has proved an effective way of finding missed stones. ${ }^{4}$

If despite repeated manipulation and irrigation calculi cannot be dislodged either from the intrahepatic ducts or from the ampulla of Vater, a duct drainage procedure may allow stones to pass later without causing symptoms. A duct drainage operation is also needed for patients with grossly dilated bile ducts, those whose ducts are full of mud or infected bile, and those (often found in the Far East) who have suppurative cholangiohepatitis-such patients may develop further stones and recurring symptoms even after having the duct opened and all stones removed. An operation that improves drainage of the bile from the common bile duct should prevent recurrent cholangitis.

Patients with grossly dilated bile ducts form the largest group needing a duct drainage procedure. They are often elderly; the duct frequently measures more than $20 \mathrm{~mm}$ in diameter, and yet often no mechanical obstruction can be found at the lower end. Sometimes the duct is so stretched that it becomes tortuous and the supraduodenal part lies horizontally. A side-to-side choledochoduodenostomy is the ideal operation for such patients. Provided the stoma is more than $25 \mathrm{~mm}$ in diameter further attacks of cholangitis are uncommon. ${ }^{5}$ In a collected series of 1255 operations recurrent cholangitis was recorded in only five cases. ${ }^{6} \mathrm{~A}$ possible objection to the operation is that the distal duct remains undrained, so that vegetable debris may accumulate and lead to infection, further stone formation, and even pancreatitis. In most of the documented series trouble with this "blind pouch" was not recorded unless the stoma was made too small. ${ }^{78}$

In those patients with only moderate bile duct dilatation (up to $15 \mathrm{~mm}$ in diameter) choledochoduodenostomy is less easy to perform satisfactorily because it is difficult to create an adequate stoma. In such patients a sphincteroplasty is a satisfactory alternative. ${ }^{910}$ The duodenum must be adequately mobilised so that it can be brought up into the wound. A fine bougie may be passed down from above to aid recognition of the ampulla and the duodenum can then be opened through a transverse incision that allows closure without any tension. The sphincter is incised superolaterally and the bile duct mucosa sutured to the duodenal mucosa to prevent later stenosis. The incision of the sphincter is continued upwards until the dilated lumen of the bile duct is reached. Complete clearance of stones from the distal duct is then easily confirmed.

The published results of sphincteroplasty are generally good. In a collected series of 1061 patients only seven had postoperative cholangitis. ${ }^{9}$ One study compared sphincteroplasty with choledochoduodenostomy and found the two operations equally effective, but the mortality rate of sphincteroplasty $(4.6 \%$ ) was slightly higher than that of choledochoduodenostomy ( $3 \%$ ).

In summary, any surgeon doing a choledochotomy should consider whether an additional duct drainage procedure is indicated. If it is, then choledochoduodenostomy (for those with grossly dilated ducts) or sphincteroplasty will give very satisfactory results. 
1 Peel, A L G, Hermon-Taylor, J, and Ritchie, H D, Annals of the Royal College of Surgeons, 1974, 55, 236

${ }^{2}$ Glenn, F, and McSherry, C K, Current Problems in Surgery, 1975, 1, 38.

${ }^{3}$ Le Quesne, L P, Proceedings of the Royal Society of Medicine, 1960, 53, 852.

4 Finnis, D, and Rowntree, T, British fournal of Surgery, 1977, 64, 661

5 Johnson, A G, and Stevens, A E, Gut, 1969, 10, 68.

${ }^{6}$ Madden, J L, et al, American fournal of Surgery, 1970, 119, 45.

Hoerr, S O, and Hermann, R E, Surgical Clinics of North America, 1973, $53,1115$.

${ }^{8}$ Freund, H, et al, Archives of Surgery, 1977, 112, 1032.

9 Thomas, C G, Nicholson, C P, and Owen, J, Annals of Surgery, 1971, $173,845$.

10 Jones, S A, Surgical Clinics of North America, 1973, 53, 1123.

\section{Penicillamine: its place in rheumatology}

It is now 22 years since Dr John Walshe treated his first patient with Wilson's disease with penicillamine. His approach was entirely logical. Here was a disease thought to be due to excess copper deposited in the body, and it had been suggested that progression of the illness might be halted if sufficient copper could be removed. Penicillamine, a metabolite of penicillin described by Abraham and his colleagues, ${ }^{1}$ was known to increase the urinary excretion of copper. Walshe therefore set out to treat Wilson's disease with this agent and furthermore predicted that it would be effective in cystinuria. In his honour a meeting was held in Cambridge in September 1976 , and the papers read at the symposium have now been published ${ }^{2}$ under the title "Penicillamine at 21." Instead of being discarded as a useless and odoriferous excretion product, penicillamine is now being, or has been, used in the treatment of Wilson's disease, cystinuria, gold and lead poisoning, scleroderma, primary biliary cirrhosis, chronic active hepatitis, muscular dystrophy, and rheumatoid arthritis.

All of these conditions are rare-with the exception of rheumatoid arthritis. What is penicillamine's place in rheumatology? One certain fact about the drug is the large number of its toxic side effects on the kidneys, the bone marrow, and the skin. In potentially fatal conditions the risk of a serious adverse reaction is more acceptable than in one which is rarely lethal such as rheumatoid arthritis. Nevertheless, Jaffe $\mathrm{J}^{3-5}$ in the United States and later Golding et $a l^{6}{ }^{7}$ in Britain, a multicentre trial group, ${ }^{8}$ Huskisson and his colleagues, ${ }^{9}$ and Hill and Hill $^{10}$ have shown clearly that penicillamine has a valuable therapeutic action in this condition. As with gold salts, close and careful monitoring is essential, and no patient should be treated with either drug unless regular blood and platelet counts, urine testing, and close clinical supervision can be maintained throughout the long period of treatment, which will probably continue for several years.

Dosage is now much more conservative than previously, and several speakers at the symposium advised starting at a daily dose of $125-250 \mathrm{mg}$ of penicillamine, increased only over some months to $750 \mathrm{mg}$ daily. Higher doses are necessary in some cases, but there is an associated increase in the risk of toxic effects. Beneficial effects from the lower doses may be delayed for several months, and treatment should therefore be continued for six months or more before being abandoned as ineffectual.

We still do not know how penicillamine acts in rheumatoid arthritis. Studies by Otsuka and Mori ${ }^{11}$ suggested that its antirheumatoid action might be attributable to its inhibition of lysosomal enzyme release in connective tissue membranes. Rucker and his colleagues ${ }^{12}$ examined the effects of inhibition of collagen cross-linking by penicillamine, and the whole subject is well reviewed by Friedman ${ }^{13}$ in the symposium.

Penicillamine has thus somewhat taken over the part formerly played by gold in treating rheumatoid arthritis. It provides an alternative to chrysotherapy for long-term treatment that has the advantage of oral as opposed to intramuscular administration. Though complications are relatively common, they are usually mild and readily controlled by reducing or stopping treatment.

Abraham, E P, et al, Nature, 1942, 149, 356.

2 Proceedings of the Royal Society of Medicine, 1977, 70, suppl 3.

3 Jaffe, I A, Arthritis and Rheumatism, 1965, 8, 1064.

$4 \mathrm{Jaffe}, \mathrm{I}$ A, Arthritis and Rheumatism, 1970, 13, 436.

5 Jaffe, I A, Arthritis and Rheumatism, 1975, 18, 513.

6 Golding, J R, Wilson, J V, and Day, A T, Postgraduate Medical fournal, 1970, 46, 599.

7 Golding, J R, et al, Proceedings of the Royal Society of Medicine, 1977, 70, suppl 3, 131 .

${ }^{8}$ Multicentre Trial Group, Lancet, 1973, 1, 275.

${ }^{9}$ Huskisson, E C, et al, Annals of the Rheumatic Diseases, 1974, 33, 532.

10 Hill, H F H, and Hill, A G S, Scandinavian fournal of Rheumatology, 1975, 4, suppl 8, 21-05.

11 Otsuka, K, and Mori, Y, Chemical and Pharmaceutical Bulletin, 1976, 24, 215.

12 Rucker, R B, et al, in Protein Cross-linking: Nutritional and Medical Consequences, ed M Friedman. New York, Plenum Press, 1977.

${ }^{13}$ Friedman, M, Proceedings of the Royal Society of Medicine, 1977, 70, suppl 3, 50 .

\section{Redundant doctors}

In most organisations-large companies, Government departments such as the DHSS, and nationalised corporationsresponsible work has for many years carried an implied promise of job security. If economic circumstances forced a cut in the number of employees there might have to be redundancies; otherwise dismissal implied incompetence or some other form of unacceptable behaviour. The Employment Protection Act gave that convention the force of law but otherwise made little difference to established practice.

The NHS hospital service is, however, a striking exception in its treatment of doctors in the training grades-as Dr Arun Baksi learnt to his cost in an appeal in December against his dismissal from his post as senior registrar at the Liverpool Royal Infirmary. Time-expired senior registrars have no security, says the DHSS. Like consultants, their contract is with the regional health authority, and any region may refuse to renew an individual senior registrar's contract after four or five years. In practice most contracts have been renewed-in 1976 there were 61 senior registrars in England and Wales who had been in post for over five years-but there is no security for these doctors while they are looking for consultant appointments.

Dr Baksi went to the Employment Appeal Tribunal-with the support of the BMA-to clarify the application of the law on employment protection to doctors in the hospital training grades. In general, every appointment, after the completion of at least 26 weeks in post, now carries the statutory right for the holder not to be "unfairly dismissed," and the non-renewal, without good reason, of a "fixed-term" contract is legally a dismissal. Furthermore, merely to describe an appointment as a "locum" post does not necessarily render the doctor freely dispensable after a long period of service.

Nevertheless, the appeal tribunal, having examined the 